\title{
MODELING PRECIPITATION DEPENDENT FOREST RESILIENCE IN INDIA
}

\author{
P. Das ${ }^{1, *}$, M. D. Behera ${ }^{2}$, P. S. Roy ${ }^{3}$ \\ ${ }^{1,2}$ Centre for Oceans, Rivers, Atmosphere and Land Sciences (CORAL), Indian Institute of Technology Kharagpur, India - \\ 1as.pulok2011@gmail.com; ${ }^{2}$ mdbehera@coral.iitkgp.ernet.in \\ ${ }^{3}$ Centre for Earth, Ocean and Atmospheric Sciences, University of Hyderabad, Hyderabad, India - ${ }^{3}$ psroy13@ gmail.com
}

ISPRS Technical Commission III (WG III/10)

KEY WORDS: Resilience, Total Annual Precipitation, Logistic Regression, Forest, Climate Regime, Change Proneness

\begin{abstract}
:
The impact of long term climate change that imparts stress on forest could be perceived by studying the regime shift of forest ecosystem. With the change of significant precipitation, forest may go through density change around globe at different spatial and temporal scale. The 100 class high resolution (60 meter spatial resolution) Indian vegetation type map was used in this study recoded into four broad categories depending on phrenology as (i) forest, (ii) scrubland, (iii) grassland and (iv) treeless area. The percentage occupancy of forest, scrub, grass and treeless were observed as $19.9 \%, 5.05 \%, 1.89 \%$ and $7.79 \%$ respectively. Rest of the $65.37 \%$ land area was occupied by the cropland, built-up, water body and snow covers. The majority forest cover were appended into a $5 \mathrm{~km}$ $\times 5 \mathrm{~km}$ grid, along with the mean annual precipitation taken from Bioclim data. The binary presence and absence of different vegetation categories in relates to the annual precipitation was analyzed to calculate their resilience expressed in probability values ranging from 0 to 1 . Forest cover observed having resilience probability $(\mathrm{Pr})<0.3$ in only $0.3 \%(200 \mathrm{~km} 2)$ of total forest cover in India, which was $4.3 \%<0.5 \mathrm{Pr}$. Majority of the scrubs and grass $(64.92 \% \operatorname{Pr}<0.5)$ from North East India which were the shifting cultivation lands showing low resilience, having their high tendency to be transform to forest. These results have spatial explicitness to highlight the resilient and non-resilient distribution of forest, scrub and grass, and treeless areas in India.
\end{abstract}

\section{INTRODUCTION}

The state of global forest cover in the regions undergoing significant climate alterations gradually changing in both the directions of stability and instability. The tendency of interstate transition of among different states of forest categories termed as resilience or alternatively the change proneness. The term resilience in forest ecosystem defines the capacity of a forest state to recover to its original state from a little perturbation due to different external forces or disturbances. The magnitude, frequency and duration of external forces and the internal resistive forces of a system define the state of that particular system. If this perturbation exceeds the internal resistive threshold value, the internal resilience declines and the ecosystem becomes vulnerable, and progressively smaller disturbances can cause shifts (Folke, et al., 2004). The external perturbations and disturbances may be climatic or non-climatic, also includes the stochastic events as forest fires, flooding, windstorms, insect, population explosions, and human activities as deforestation, use of pesticide, introduction of exotic plant or animal species. In response to the global climate change, the forest cover of India is also undergoing change through degradation because of the increasing anthropogenic pressure and climate change. In addition to climate, other variables such as topography, soil characteristics, human activities, landscape parameters, herbivory plays important role. The transition of forest cover can take place either by forest loss or gain or change in density. Resilience state of Indian forest cover according to the climatic conditions is the aim of the current study. In previous global to regional studies on forest resilience, the tree canopy cover density map have been used as the input map of forest cover distribution (Hirota et al., 2011; Staver et al., 2011; Keersmaecker et al., 2015; Behera et al., 2018). The forest type map of Champion and Seth (1968) was used study of forest cover resilience in India (Chaturvedi et al., 2010). The transitions between the different vegetation types follow an order of either decreasing or increasing trend, e.g. with three vegetation type as forest, savannah and treeless, the forest cover shows change proneness towards the its nearest stable state of savannah only, whereas the savannah shows change proneness to its either states as forest or treeless state and the treeless state shows change proneness towards the savannah. The probability of change proneness or complementarily the resilience can be modelled using the vegetation type map, driving forcing or simply drivers through statistical approaches or models as logistic regression, generalized additive model (GAM), Integrated Biosphere Simulator (IBIS) (Hirota et al., 2011; Staver et al., 2011; Behera et al., 2018; Chaturvedi et al., 2010). In the current study the binary logistic regression technique was adopted for estimating the forest cover resilience. The logistic regression or logit regression or logit model by statistician D. R. Cox in 1958 is used to predict a binary response (presence or absence) based on one or more predictor variables in estimating their quantitative and qualitative response.

\section{STUDY AREA}

The Indian mainland with an estimated area of 330 Mha has been selected as the current study area (Fig 1). The spatial extension of the Indian mainland roughly varies from $80 \mathrm{oN}$ to $37 \mathrm{oN}$ and $68 \mathrm{oE}$ to $98 \mathrm{oE}$. According to climatic conditions, India is categorized into four board climatic zones as (i) Equatorial humid, (ii) Equatorial winter wet and dry, (iii) Arid and Semi-arid, (iv) Montane (Köppen-Geiger). Distinct climatic and also topographic variability can be observed into these climatic zones. The mean precipitation observed as $3187 \mathrm{~mm}$ in Equatorial humid includes the world's highest precipitated area as Cherrapunji-Mawsynram region receives average annual precipitation of around $12,000 \mathrm{~mm}$ in the hilly northeastern state of Meghalaya; $1572 \mathrm{~mm}$ in Equatorial winter wet and dry; $437 \mathrm{~mm}$ in Arid and Semi-arid and $618 \mathrm{~mm}$ in Montane region The temperature varies from a minimum of $-130 \mathrm{C}$ (Leh) to a daily maxima occasionally reaches $50 \mathrm{oC}$ in tropical dry regions as Rajasthan. The mean elevation of Indian mainland varies from mean sea level to around $8500 \mathrm{~m}$, contains the third highest mountain peak of the world as Kangchenjunga. The total Indian 
population as per the Census 2011 was observed to be 1.21 billion.
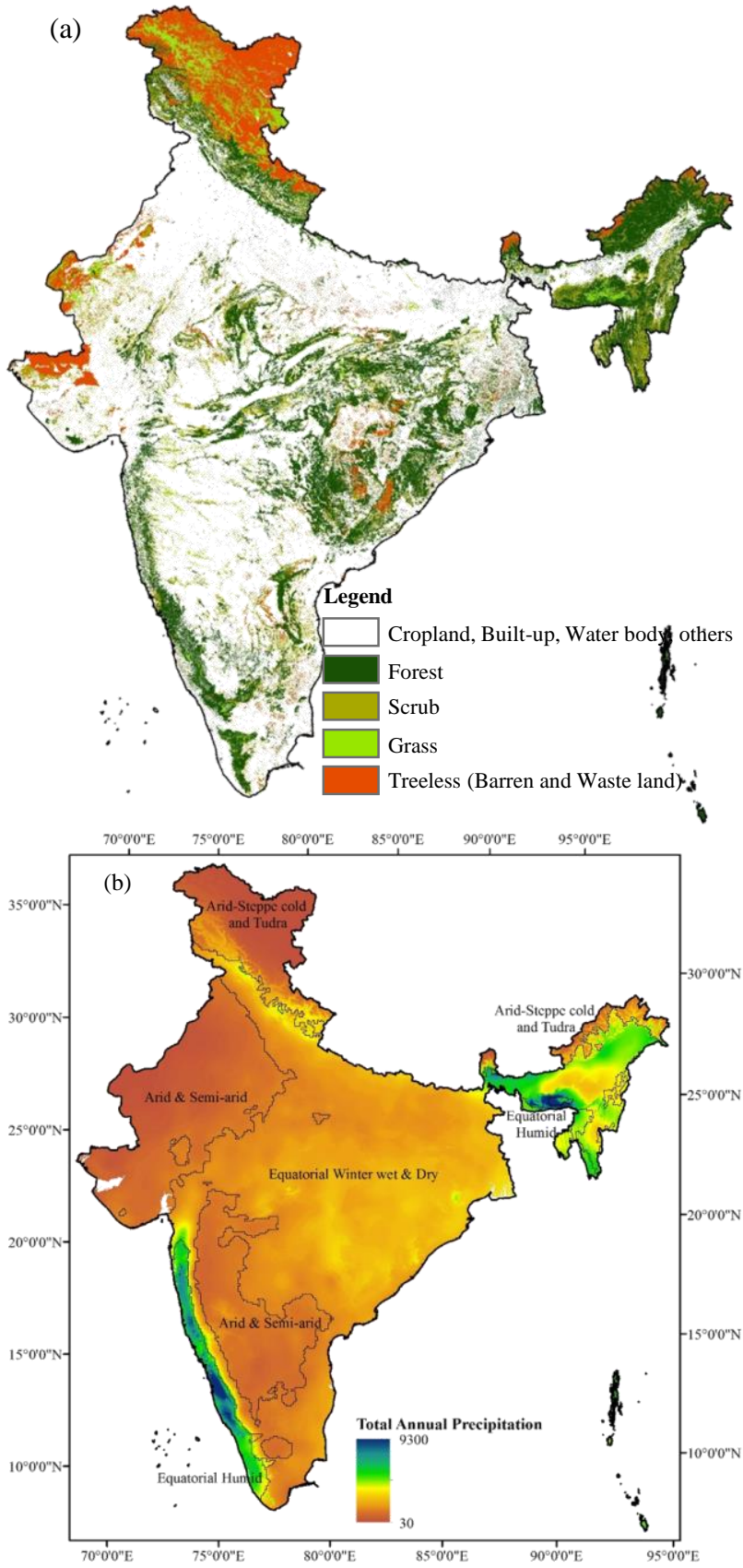

Figure 1: (a) Forest cover map of India (Adopted from Roy et al., 2015 and reclassified); (b) Four broad climate zone (Köppen-Geiger) overlaid on total annual precipitation map of India

\section{DATA AND METHODOLOGY}

The high resolution 100 class India vegetation type map $(60 \mathrm{~m}$ res) prepared at 1:50,000 scale using the seasonal LISS-III and Landsat satellite remote sensing data have been used in this study (Roy et al., 2015). For accuracy assessment, 15,685 number of field sample plots taken with GPS co-ordinate. Assistance-ship was taken from the biogeographic maps (Rodgers et al., 1988), digital elevation model (SRTM DEM), topographical maps (scale 1:50,000). The India vegetation map were categorized into four broad groups based on the phrenology as (a) forest, (b) scrub (c) grass and (d) treeless area excluding the croplands, water body, built-up, snow \& ice classes (Fig 1). The majority forest cover in appended into a $5 \mathrm{~km} \times 5 \mathrm{~km}$ grid, along with the mean annual precipitation taken from Bioclim data. The binary presence and absence of forest category was fitted with the total precipitation using binary logistic regression models rather than continuous models. The model approach can be expressed as follows:

Let, $\mathrm{Yi}=1$ and 0 , represented the presence or absence in the observation, $\mathrm{b}$ was the coefficients associated with the variable $\mathrm{X}$ (precipitation)

$$
\operatorname{Logit}\left(Y_{i}\right)=\ln \left[Y_{i} /\left(1-Y_{i}\right)\right]=a+b x
$$

The resilience state of each forest category was expressed in probability values in a scale of 0 to 1 . Higher resilience probability corresponds to high stability and lesser tendency to shift to alternative stable state and vice-versa. Mathematically the resilience probability (Pr) in can be expressed as follows:

$$
P_{r}=\frac{1}{1+\exp (-(a+b x))}
$$

\section{RESULTS AND DISCUSSION}

The India vegetation type map recoded into four vegetation where the non-vegetated areas as cold deserts, settlement, barren land, river bed, water body, wet lands and agricultural lands were reclassified as treeless area (Table 1). Degraded forest, woodland, shifting cultivation and jhum were classified as the scrubland cover. Out of total geographic area of India, $6,71,025 \mathrm{~km}^{2}$ areas were observed to be forest, with scrubland and grassland cover of $1,70,300 \mathrm{~km}^{2}$ and $63,625 \mathrm{~km}^{2}$ respectively, and with treeless cover of 2,62,675 (Table 1). Out of the $22,03,775 \mathrm{~km}^{2}$ remaining area were observed to be occupied with the agriculture land, water body, snow-ice and settlement area.

Table 1: Forest and other land cover area statistics

\begin{tabular}{lc}
\hline \multicolumn{1}{c}{ Class } & Area in $\mathbf{~ k m}^{\mathbf{2}}(\mathbf{\%})$ \\
\hline Treeless & $262675(7.79)$ \\
Grass & $63625(1.89)$ \\
Scrub & $170300(5.05)$ \\
Forest & $671025(19.9)$ \\
Cropland, Water, Built-up, Snow & $2203775(65.37)$ \\
\hline
\end{tabular}

The equatorial humid climate regime includes the high altitude areas of Himalayan belt and the western ghat receives moderate to high precipitation (average annual precipitation [ppt: $3187 \mathrm{~mm}]$ ). The plains of Brahmaputra, Ganga and Mahanadi river basins comes under the equatorial winter wet and dry climate regimes, receives $1572 \mathrm{~mm}$ annual precipitation. The arid and semi-arid regions includes the West part of India as Rajasthan, Gujarat and Southern regions receives lowest precipitation in India as $437 \mathrm{~mm}$ of annually. The transHimalayan and deserts of Rajasthan receives less precipitation; about $620 \mathrm{~mm}$ of annual precipitation.

The results of logistic regression is given in table 2 . The applied logistic regression for intra-class transition between forest to scrub \& grass was observed with $R^{2} 0.23$ as with overall prediction accuracy of $83 \%$. The corresponding intra-class transition between scrub \& grass to treeless was observed with $R^{2} 0.57$ as with overall prediction accuracy of $87 \%$. 
Table 2: The statistics of binary logistic regression

\begin{tabular}{llllll}
\hline \multicolumn{2}{c}{ Transition type } & $\boldsymbol{R}^{2}$ & $\begin{array}{c}\text { Overall accuracy } \\
(\%)\end{array}$ \\
\hline $\begin{array}{l}\text { Forest to } \\
\text { Grass }\end{array}$ & Scrub & $\&$ & 0.23 & & 83 \\
$\begin{array}{l}\text { Scrub \& } \\
\text { Treeless }\end{array}$ & Grass & to & 0.57 & 87 \\
\hline
\end{tabular}

The probability of resilience of each forest type under each climatic regime is shown in Fig 2, and the corresponding area statistics is given in table 3 . Out of total forest covers in India, only $0.03 \%$ forest cover have resilience probability below 0.3 , which were observed in arid \& semi-arid regions that receives less amount of annual precipitation $(436 \mathrm{~mm})$. The resilience probability value of 0.5 for forest covers observed at the annual precipitation of $719 \mathrm{~mm}$, which was $160 \mathrm{~mm}$ for 0.3 resilience probability. More than $96 \%$ of the forest covers were observed in equatorial humid, equatorial winter wet and dry regions and montane (Western Ghats, North east India, and eastern regions), where about $94 \%$ forest were observed highly resilient $(\operatorname{Pr}>0.5)$ as they receives sufficient annual precipitation and $2 \%$ forest observed to have resilience probability between 0.3 and 0.5 . Out of $4 \%$ of total forest cover, only $0.03 \%$ forest in dry arid \& semi-arid regions observed least resilient and around 2.20\% forest observed resilience probability between 0.3 and 0.5 . About $37.53 \%$ scrub and grass of total cover observed to have resilience probability $<0.3$, which were mostly observed in the highly precipitated regimes of North east and eastern India. Whereas the scrubs and grass from dry regions were observed to be comparatively resilient with competition to forest cover as they favours wet climate. On the other hand, the scrubs and grass of the equatorial humid, winter wet and dry regions which are highly precipitated were observed highly resilient with competition to treeless, i.e., their change proneness to treeless is very low, rather they are more prone to shifts towards forest. Around $22.11 \%$ scrub and grass of the dry arid, semi-arid and montane region have below 0.3 resilience probability exhibiting change proneness towards treeless. Following the same trend, most of the treeless covers of the dry Montane and arid, semiarid region were observed resilient due to dryness, whereas of the equatorial winter wet and dry have less resilience or change proneness due to sufficient annual precipitation. Around $14.45 \%$ treeless observed to have less than 0.3 resilience probability observed in the equatorial winter wet and dry and its transition zone with montane climate regime in north India. Most of the scrubs lands from North east India were identified as the scrub mapped were the jhum lands (shifting cultivation lands) which were resilient forest undergone through repeated deforestation from past several decades.

Out results clearly supports the observation of Hirota et al. (2011), as with increase in precipitation, the resilience of treeless decreases shows change proneness to scrub and grass, whereas scrub and grass shows succession and exhibits change proneness towards forest. With decrease in precipitation, forest shows change proneness towards scrub-grass; whereas scrubgrass shows change proneness towards treeless.
Table 3: Area statistics (in \%) of the state of resilience in each forest category

\begin{tabular}{|c|c|c|c|c|c|c|}
\hline & & Probability & $\begin{array}{c}\text { Forest } \\
- \\
\text { Scrub } \\
\& \\
\text { Grass } \\
\end{array}$ & $\begin{array}{c}\text { Scrub } \\
\& \\
\text { Grass } \\
- \\
\text { Forest } \\
\end{array}$ & $\begin{array}{c}\text { Scrub \& } \\
\text { Grass - } \\
\text { Treeless }\end{array}$ & $\begin{array}{l}\text { Treeless } \\
- \text { Scrub } \\
\text { \& Grass }\end{array}$ \\
\hline \multirow{16}{*}{ 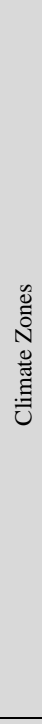 } & \multirow{4}{*}{$\begin{array}{c}\text { Equatorial } \\
\text { Humid }\end{array}$} & $<0.3$ & 0 & 3.66 & 0 & 0.10 \\
\hline & & $0.3-0.5$ & 0 & 0 & 0 & 0 \\
\hline & & $0.5-0.75$ & 0.01 & 0 & 0 & 0 \\
\hline & & $0.75-1$ & 11.09 & 0 & 3.66 & 0 \\
\hline & \multirow{4}{*}{$\begin{array}{c}\text { Equatorial } \\
\text { Winter wet } \\
\text { and dry }\end{array}$} & $<0.3$ & 0 & 30.57 & 0 & 8.27 \\
\hline & & $0.3-0.5$ & 1.12 & 17.72 & 0 & 0.24 \\
\hline & & $0.5-0.75$ & 37.33 & 0.71 & 2.89 & 0 \\
\hline & & $0.75-1$ & 34.93 & 0 & 46.10 & 0 \\
\hline & \multirow{4}{*}{$\begin{array}{c}\text { Arid \& } \\
\text { Semi-arid }\end{array}$} & $<0.3$ & 0.03 & 0 & 7.42 & 0.37 \\
\hline & & $0.3-0.5$ & 2.20 & 2.30 & 3.46 & 1.15 \\
\hline & & $0.5-0.75$ & 1.79 & 15.13 & 6.17 & 6.02 \\
\hline & & $0.75-1$ & 0 & 0 & 0.38 & 11.45 \\
\hline & \multirow{4}{*}{ Montane } & $<0.3$ & 0 & 3.31 & 14.69 & 5.81 \\
\hline & & $0.3-0.5$ & 0.96 & 7.37 & 2.40 & 4.95 \\
\hline & & $0.5-0.75$ & 6.23 & 19.24 & 3.91 & 12.70 \\
\hline & & $0.75-1$ & 4.32 & 0 & 8.91 & 48.96 \\
\hline & \multirow{4}{*}{ Overall } & $<0.3$ & 0.3 & 37.53 & 22.11 & 14.54 \\
\hline & & $0.3-0.5$ & 4 & 27.39 & 5.87 & 6.34 \\
\hline & & $0.5-0.75$ & 45.36 & 35.08 & 12.96 & 18.71 \\
\hline & & $0.75-1$ & 50.34 & 0 & 59.06 & 60.41 \\
\hline
\end{tabular}

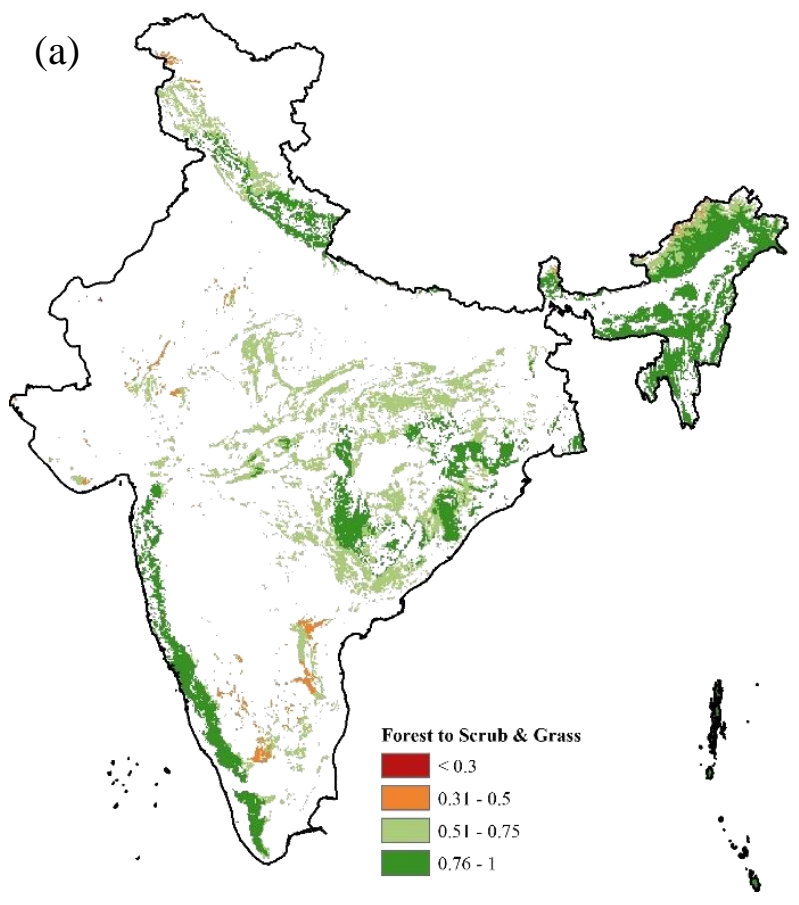



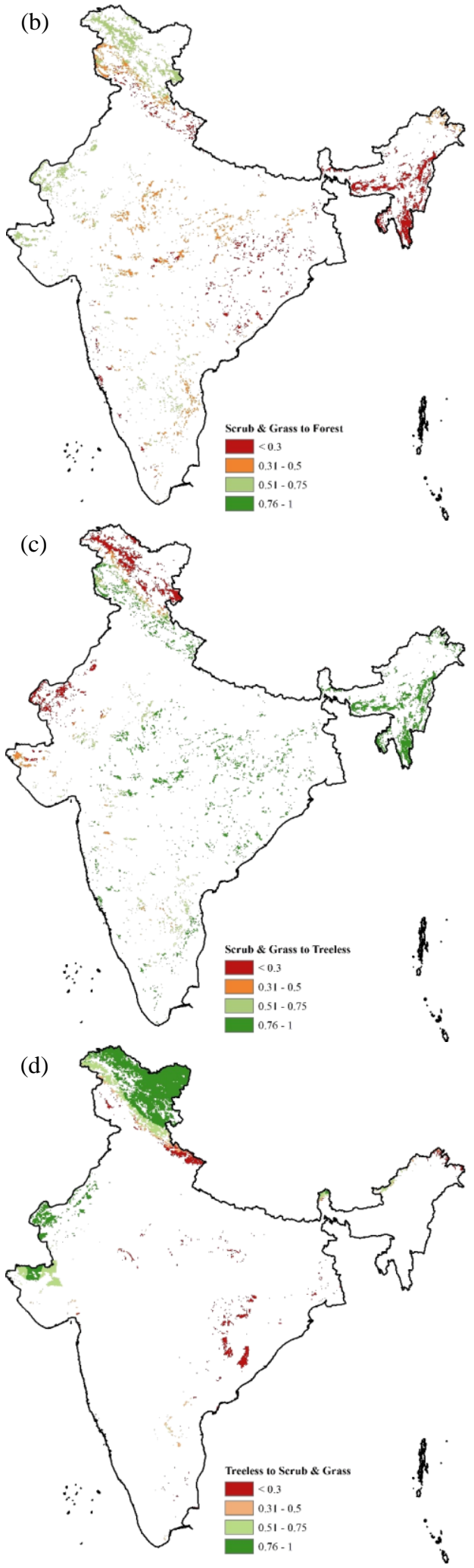

\section{CONCLUSIONS}

The well fitted logistic regression between treeless and scrubgrass clearly defines their favourable precipitation regimes. However, the performance was less significant in case of forest with competition to scrub-grass, as they have large overlapping suitable precipitation regimes. The resilient scrubs of high altitude montane region could be showing high change prone to forest, however, the seasonal temperature may be the limiting factor. With this clue, the resilience in each climate regime may add bias the results. Across the landscape, in different subregions, the impact of same amount of precipitation would be different. Instead, the entire scale of precipitation allowed in identifying significant presence and absence of different forest cover. Hirota et al. (2011), Bucini and Hanan (2007), Staver et al. (2011), all have applied same model for continental and inter-continental scale. Hirota et al. (2011) have observed the best fit model for intercontinental scale, i.e., as at this scale the sigmoid function best fitted with observed data points. Staver et al. (2011), Bucini and Hanan (2007) have also described that at local scale there could be inconsistence impact of variables, that vary substantially at large or continental scale.

\section{REFERENCES}

Behera, M. D., Das, P., Murthy, M. S. R., Uddin, K., and Sharma, E., 2018. Mod.eling Forest Resilience in Hindu Kush Himalaya using Geo-information, Journal of Earth System Science (Acepted).

Chaturvedi, R. K., Gopalakrishnan, R., Jayaraman, M., Bala, G., Joshi, N. V., Sukumar, R., and Ravindranath, N. H. 2010. Impact of climate change on Indian forests: a dynamic vegetation modelling approach, Mitigation and Adaptation Strategies for Global Change, 16(2), 119-142, DOI 10.1007/s11027-010-9257-7

De Keersmaecker, W., Lhermitte, S., Tits, L., Honnay, O., Somers, B., and Coppin, P., 2015. A model quantifying global vegetation resistance and resilience to short-term climate anomalies and their relationship with vegetation cover, Global Ecology and Biogeography, 24(5), 539-548, DOI: 10.1111/geb.12279

Folke, C., Carpenter, S., Walker, B., Scheffer, M., Elmqvist, T., Gunderson, L., and Holling, C. S. 2004. Regime shifts, resilience, and biodiversity in ecosystem management, Annual Review of Ecology, Evolution, and Systematics, 557-581, DOI: 10.1146/annurev.ecolsys.35.021103.105711

M. Hirota, M. Holmgren, E. H. Van Nes, and M. Scheffer, 2011. Global resilience of tropical forest and savanna to critical transitions, Science, 334(6053), 232-235, DOI: 10.1126/science. 1210657

Peel, M. C., Finlayson, B. L., and McMahon, T. A., 2007. Updated world map of the Köppen-Geiger climate classification. Hydrology and earth system sciences discussions, 4(2), 439-473.

Rodgers, W.A. and Panwar, S.H., 1988. Biogeographical Classification of India. New Forest, Dehradun, India.

Roy, P. S., Behera, M. D., Murthy, M. S. R., Roy, A., Singh, S., Kushwaha, S. P. S., ... and Gupta, S. 2015. New vegetation type map of India prepared using satellite remote sensing: Comparison with global vegetation maps and utilities, International Journal of Applied Earth Observation and Geoinformation, 39, 142-159, DOI: 10.1016/j.jag.2015.03.003 Staver, A. C., Archibald, S., and Levin, S. A. 2011. The Global Extent and Determinants of Savanna and Forest as Alternative Biome States, Science, 334, 230, DOI: 10.1126/science. 1210465

Data source: Bioclim: Hijmans, R. J., Cameron, S. E., Parra, J. L., Jones, P. G., \& Jarvis, A 2005. Very high resolution interpolated climate surfaces for global land areas, International Journal of Climatology, 25: 1965-1978, DOI: 10.1002/joc.1276 